\title{
LA REGULACIÓN DE LOS INTERMEDIARIOS DE SEGUROS EN COLOMBIA: UN RÉGIMEN DE SUPERVISIÓN ASIMÉTRICO*
}

\author{
COLOMBIAN REGULATION OF INSURANCE \\ INTERMEDIARIES: AN ASYMMETRIC SUPERVISION \\ SCHEME
}

CARLOS DANIEL VERGARA ARREGOCÉS ${ }^{* *}$

Fecha de recepción 25 de mayo de 2019

Fecha de aceptación 30 junio de 2019

Disponible en línea: 15 de septiembre de 2019

Para citar este artículo/To cite this article

Vergara Arregocés, Carlos Daniel, La regulación de los intermediarios de seguros en Colombia: un régimen de supervisión asimétrico, 50 Rev.Ibero-Latinoam.Seguros, 83-118 (2019). https://doi.org/10.11144/Javeriana.ris50.risc

doi:10.11144/Javeriana.ris50.risc

Este artículo es una adaptación con supresiones del Trabajo de Grado para obtener el grado de especialista en Derecho de Seguros presentado en noviembre de 2018.

** Abogado de la Universidad de Los Andes, especialista en Derecho de Seguros y en Responsabilidad y Daño Resarcible de la Pontificia Universidad Javeriana y la Universidad Externado de Colombia respectivamente. Actualmente se desempeña como profesor asistente de la cátedra de Responsabilidad Civil en la Universidad de Bogotá Jorge Tadeo Lozano y es asociado del equipo de Seguros y Reaseguros de Brigard Urrutia. https://orcid.org/0000-0002-9935-986X Contacto: cd.vergara166@, gmail.com 


\section{RESUMEN}

En Colombia existen los denominados intermediarios tradicionales de seguros, a saber, las agencias de seguros, los agentes de seguros y las sociedades corredoras de seguros, todos regidos por particularidades normativas que los distinguen entre ellos. El presente trabajo hace un estudio de la regulación de estas figuras en nuestro país, incluyendo las interpretaciones que el supervisor (Superintendencia Financiera) y la jurisprudencia hacen de ella, haciendo cuestionamientos críticos que exhiben los efectos prácticos de esta normatividad en el mercado asegurador.

Palabras clave: Agencias; Corredores; Intermediarios; Regulación 


\begin{abstract}
In Colombia, there are insurance intermediaries like agencies, agents and brokers, also known or classified as traditional intermediaries, which, as will be seen later, have multiple regulatory particularities distinguishing them from each other. This paper pursues an study of the regulation of these subjects in our country, exhibiting the way it is construed by the supervisor (Financial Superintendence), and making critical inquiries that enables the reader to identify effects of this regulation in the insurance market.
\end{abstract}

Keywords: Agencies; Brokers; Intermediaries; Regulation

\title{
SUMARIO
}

\section{INTRODUCCIÓN - 1. LAS AGENCIAS Y LOS AGENTES DE SEGUROS}

- 1.1. Entre los contratos de agencia mercantil y agencia de seguros - 1.2. Dirección y constitución de las agencias de seguros - 1.3. La naturaleza del agente de seguros - 1.4. Las agencias y agentes de seguros como representantes de las entidades aseguradoras - 1.4.1. Fuente normativa - 1.4.2. Problemática - 1.4.3. La institución de la intermediación y su vínculo con la representación - 1.5. Las agencias asimiladas a corredores - 1.6. El esquema de supervisión indirecta sobre las agencias y agentes de seguros - 1.6.1 Aspectos generales sobre la supervisión - 1.6.2. La supervisión indirecta - 2. LAS SOCIEDADES CORREDORAS DE SEGUROS - 2.1. Aspectos generales - 2.2. Objeto social ¿exclusivo? - 2.2.1 Apertura del mercado para la adquisición de seguros por parte de las entidades del sector público - 2.2.2. Reforma estructural del Sistema de Seguridad Social - 2.2.3. Efectos de las regulaciones complementarias - 2.3. La constitución de sociedades corredoras de seguros como entidad vigilada por la superintendencia financiera de Colombia - 2.4. El carácter independiente de los corredores - CONCLUSIONES - REFERENCIAS. 



\section{INTRODUCCIÓN}

El presente trabajo tiene por objeto hacer un análisis del desarrollo normativo y jurisprudencial sobre la naturaleza jurídica de los intermediarios de seguros desde una perspectiva crítica, planteando algunas falencias normativas e interpretativas y sus correspondientes oportunidades de mejora.

Se evidencian falencias en la regulación colombiana, principalmente porque el régimen asimétrico de supervisión exige mucho de algunos actores, como las sociedades corredoras y las entidades aseguradoras, y deja un amplísimo marco de actuación tanto para agencias como para agentes. Si bien los motivos que llevaron a la adopción del actual modelo de supervisión resultan adecuados, y su ejecución es generalmente idónea, sus falencias emanan de su ejecución rígida en algunos casos, y en otros, de la interpretación que la administración de justicia y la Superintendencia Financiera hacen de ella.

\section{LAS AGENCIAS Y LOS AGENTES DE SEGUROS}

\subsection{Entre los contratos de agencia mercantil y agencia de seguros}

La cotidianidad con la que se habla de la agencia o el agente de seguros en cierta manera relega o desenfoca la atención sobre la connotación que tiene la agencia en la legislación mercantil colombiana por ser un negocio jurídico típico regulado en el Código de Comercio expedido en 1971.

En la agencia mercantil el agente promueve o explota negocios en una zona prefijada del territorio nacional en calidad de representante del propietario de los mismos, es decir, el agenciado, aclarando que este, salvo pacto en contrario, no podrá valerse de varios agentes en el mismo espacio geográfico y deberá remunerarlo en caso de hacer negocios directamente en el área asignada para su representante sin la intervención de este último. Por su parte, las agencias y agentes de seguros representan a una o varias compañías aseguradoras en un territorio, que puede ser compartido por 
varias agencias/agentes representando al mismo asegurador y en el que el asegurador podrá operar sin la intervención de su representante, caso en el que no se genera remuneración alguna para el agente.

Asimismo, la agencia mercantil es una institución concebida para que el agente, aun actuando a nombre propio, logre la remuneración del agenciado y el posicionamiento de su negocio que le crean un activo intangible del cual podrá seguir disfrutando, incluso después de terminado el vínculo con el agente. En contraposición, las agencias/agentes de seguros representan a los aseguradores en las facultades mínimas previstas en la ley (Ley 65, 1996), en la tarea de aproximación para el perfeccionamiento contratos de seguro en lo ramos que le hayan sido autorizados por el asegurador, y por regla general, los tomadores y/o asegurados permanecen ligados al intermediario mas no al asegurador.

La agencia de seguros no es una clasificación de la agencia mercantil por lo que su normatividad no le es aplicable, ni siquiera en forma supletiva, ${ }^{-1}$ puesto que cada una cuenta con su propia regulación; exhaustiva en el caso de la comercial al hacer remisión expresa a las normas del mandato y contemplar formas de terminación del contrato, al paso que la de seguros se rige exclusivamente por sus propias normas y la finalización del vínculo se ciñe a la discrecionalidad del asegurador, en primera medida, y al cumplimiento del régimen de inhabilidades e incompatibilidades.

Por último, si bien la tesis actual de la SFC excluye a las agencias de su supervisión, la normatividad financiera prohíbe por completo la delegación de profesionalidad debido a que las autorizaciones se emiten intuitu personae, $\underline{\underline{2}}$ por acreditar idoneidad $\underline{3}$ cuestión que, en contraste, es válida en la agencia mercantil.

\footnotetext{
1 Corte Suprema de Justicia. (2001). Expediente 5817. Octubre 22/01. Sala de Casación Civil. MP Jorge Antonio Castillo Rúgeles. Bogotá, Colombia.

2 Superintendencia Financiera de Colombia. (1996). Concepto 96023487-3 (23 de agosto, 1996). Concepto. Diferencias. Derechos del agente. Delegación de la profesionalidad. Bogotá.

3 Superintendencia Financiera de Colombia. (2015). Circular Externa 50 . Ref.: Instrucciones sobre los requisitos de idoneidad para la intermediación de seguros, el deber de información frente a los consumidores de seguros y el Sistema Unificado de Consulta de Intermediarios de Seguros. Bogotá.
} 


\subsection{La reforma en concreto}

Lo primordial es establecer que la expedición de la Ley 65 de 1966 y el EOSF mantuvieron el mismo texto relativo a la dirección de las agencias que dispuso que estas podrán ser dirigidas por una persona natural o jurídica, y de igual modo, el EOSF limitó la posibilidad de hacerlo a través de personas jurídicas, a que su forma social sea la de las sociedades colectivas, en comandita simple o de responsabilidad limitada conforme a las normas mercantiles vigentes en la materia.

Si se hace una interpretación exegética de las normas rectoras, la circunscripción a ciertos tipos societarios se predicaría exclusivamente de la dirección de la agencia, y se abren de este modo múltiples posibilidades que pueden inducir al error, máxime cuando las altas cortes y la misma Superintendencia afirman que las personas jurídicas para ser agencia, únicamente podrán constituirse como sociedades colectivas, en comandita simple o de responsabilidad limitada.

Tan es así que mediante la Sentencia C-354 de 2009 la Corte Constitucional respaldó esta posición al pronunciarse frente a una demanda en contra del numeral 3 del artículo 41 del EOSF, en donde el demandante arguyó que esa interpretación de la Superfinanciera sobre la norma, vulneraba el derecho de asociación ${ }^{4}$ (Corte Constitucional, Sala Plena, Sentencia C-354, 2009). En el fallo, se citó a la SFC y su interpretación del término "dirección":

Ahora, en torno a las apreciaciones efectuadas en la consulta, es importante subrayar que el vocablo "dirección", utilizado en el texto de las normas transcritas tiene un sentido amplio, no se refiere este simplemente al manejo de la agencia por parte de la persona que tiene a su cargo la administración del negocio, sino de la empresa organizada para la actividad de colocación de seguros (Superintendencia Financiera de Colombia, Concepto 2006065802-004, 2007; Decreto 2555, 2010).

En juicio del autor del presente texto, los argumentos del Supervisor nacional en materia de seguros podrían llegar a ser suficientes y razonables a la luz de la definición de agencia de seguros incluida en la Ley 65 de 4 Corte Constitucional. (2009). Sentencia C-354 . Sala Plena. M.P.: Gabriel Eduardo Mendoza Martelo. Bogotá. 
1966, que dispone que se trata de una oficina encargada del ejercicio de las labores que la ley le permite, es decir, la persona jurídica que adoptó una de las formas societarias que la regulación le permite y dirige su oficina denominada agencia de seguros. Sin embargo, la posición omite que el legislador contempló la posibilidad de que las agencias sean dirigidas también por personas naturales, por lo que ese sentido amplio al que se hace referencia en el oficio citado no desarrolla una de las posibilidades previstas normativamente, que de por sí, haciendo extensiva esa interpretación, no tendría ningún asidero ya que las agencias necesariamente serán personas jurídicas, mientras que la persona natural que se dedique a la misma actividad será un agente de seguros.

Finalmente, se quiere advertir al lector que la discusión se encuentra superficialmente zanjada y por ello encontrará referencias a las normas en cuestión de manera indiscriminada; como sucede en el siguiente oficio de la Superfinanciera:

Tratándose de agencias de seguros aun cuando la norma antes mencionada adolece de técnica legislativa que induce a diversas interpretaciones, lo cierto es que de su lectura resulta evidente que el legislador no previó que las agencias de seguros puedan ser dirigidas por sociedades anónimas, pues no hace mención a estas sino a las sociedades comerciales allí señaladas. (Subrayado fuera de texto)

\subsection{La naturaleza del agente de seguros}

El artículo 41 del Estatuto Orgánico del Sistema Financiero los define como las personas naturales que promueven la celebración de contratos de seguro y su renovación en relación con una o varias compañías de seguros. Estos a su vez se pueden clasificar entre agentes dependientes y agentes independientes según las características de su vínculo con la entidad aseguradora, así:

5 Superintendencia Financiera De Colombia. (2004). Concepto 2004019002-1 (20 de mayo, 2004). Estatutos excepcionales; personas autorizadas para desarrollar la actividad. Bogotá. 
a. Agentes dependientes: son aquellas personas que se encuentran vinculadas a una entidad aseguradora por medio de un contrato laboral.

b. Agentes independientes: son aquellas personas que ejercen las labores mencionadas por sus propios medios, sin dependencia alguna de la compañía de seguros con las cuales se encuentra vinculado a través de un contrato mercantil. En esta modalidad no se podrán pactar cláusulas de exclusividad que impidan a los agentes celebrar contratos con otras compañías de seguros.

\subsection{Las agencias y agentes de seguros como representantes de las entidades aseguradoras}

\subsubsection{Fuente normativa}

El aspecto de la representación es considerado por muchos como el principal rasgo distintivo entre las tipologías de intermediarios existentes en Colombia desde que la Ley 65 de 1966, instaló que las agencias representan a una o varias compañías de seguros dentro de un territorio determinado, aspecto que posteriormente fue incluido con una redacción bastante similar en el artículo 41 del EOSF.

De modo que la Corte Suprema de Justicia y la Corte Constitucional cuando han tenido la oportunidad de pronunciarse al respecto, acudiendo con claridad y simpleza a la normatividad aplicable, ponen de presente que la principal diferencia es que las agencias y los agentes ejercen representación de las compañías de seguros, mientras que los corredores ejercen su labor de intermediación de manera autónoma e independiente. ${ }^{6}$

Asimismo, el Decreto 2605 de 1993, recogido posteriormente en el Decreto 2555 de 2010, solemnizó normativamente las consecuencias de la representación que ejercen las agencias y los agentes por mandato legal, al indicar que las actuaciones de estos intermediarios obligan a la entidad aseguradora, que es parte en el contrato intermediado, mientras que el intermediario continúe vinculado a ella.

6 Corte Constitucional. (2009). Sentencia C-354 . Sala Plena. M.P.: Gabriel Eduardo Mendoza Martelo. Bogotá. 
Aclaración basilar sobre el aspecto de la representación es que, salvo pacto en contrario, el carácter representativo se puede predicar únicamente respecto de las facultades mínimas contenidas en el artículo 42 del EOSF que son recaudar dineros, inspeccionar riesgos, intervenir en salvamentos y promover la celebración de contratos de seguro.

En contraste con la tendencia legislativa que inclinó la balanza por las agencias y los agentes como representantes de las entidades aseguradoras, el Decreto 655 de 1925 contenía una definición de agencias y agentes según la cual se entendía como agente de compañías de seguros a toda persona que interviniere de cualquier manera, directa o indirectamente, por cuenta de terceros, en la celebración de negocios de seguros. ${ }^{?}$

Lo anterior es desigual a la figura de la representación de ese tercero pues resulta innegable que la representación al momento de tomar el seguro, normativamente, radica en la disposición del artículo 1038, que indica que el tomador debe tener poder y la consecuente representación para contratar en nombre del tercero, pues de lo contrario, el asegurador requerirá una ratificación por parte del representado.

Sobre este punto, es necesario concluir que la legislación inicial, expedida en 1925, al considerar a las agencias y los agentes como intermediarios para contratar por cuenta de terceros, no los percibía como representantes de las entidades aseguradoras, empero, sugiere que al contratar por cuenta de un tercero, su finalidad es velar por los intereses del asegurado frente al asegurador.

\subsubsection{Problemática}

El doctor Andrés Ordóñez consideró que el fenómeno de la representación que la ley confiere a los agentes y las agencias de seguros obedece a una reproducción de normas anti-técnicas, debido a que las agencias y las compañías aseguradoras ya se encuentran vinculadas a través del contrato de agencia, sin embargo, la redacción del texto normativo las confunde con dependencias administrativas de las entidades aseguradoras al asignarles facultades representativas de carácter general. Adicionó el mismo autor, que muy probablemente esta confusión legislativa provenga de una mala interpretación del instituto de los intermediarios de seguros 7 Ibídem 
en el derecho francés, concretamente con la institución de los denominados "agentes generales" quienes no solo representan a los aseguradores para efectos de la suscripción del contrato si no que simultáneamente, similar a lo que ocurre con la agencia mercantil, estos agentes gozan de la exclusividad para representar a la entidad aseguradora en un determinado territorio..

Esta concepción de representación ha sido prácticamente un principio axiomático, cuyo alcance se encuentra altamente demarcado en el desarrollo legislativo y jurisprudencial en el campo de la intermediación de seguros, e incluso, es uno de los principales fundamentos para el esquema de supervisión adoptado por Colombia en la actualidad.

Con lo anterior lo que se desea poner de relieve es que las agencias y los agentes en la práctica suponen una dicotomía interesante, esto debido a que por expresa disposición legal ostentan la representación de las entidades aseguradoras; por ello en teoría, sus actuaciones que afecten al consumidor financiero, obligan a la entidad aseguradora 9

De ahí que el carácter representativo al ser mal interpretado puede dar lugar a situaciones bastante complejas, pues se trata de una figura de expresa consagración legal muy propicia para suscitar conflictos de interés ya que en la práctica agencias y agentes velan por los intereses de los asegurados frente a los aseguradores.

\subsubsection{La institución de la intermediación y su vinculo con la representación}

En Colombia no se cuenta con una definición legal de intermediario, ni de sus alcances, pero lo cierto es que en la doctrina y legislación italiana, que históricamente ha servido como punto de referencia para el legislador local, se ha desarrollado extensamente el fondo estructural de la figura. 8 Ordóñez, A. (2012). Estudios de Seguros. Bogotá: Universidad Externado de Colombia.

9 El Decreto 2281 (25 de junio, 2010) establecía lo siguiente: "Las actuaciones que realicen las agencias y los agentes de seguros y de títulos de capitalización, que afecten a sus consumidores financieros, en la medida en que son representantes de las entidades aseguradoras y sociedades de capitalización, son responsabilidad de la entidad aseguradora y de la sociedad de capitalización, y por tanto, de competencia del Defensor del Consumidor Financiero de estas" (Art. 1 parágrafo). 
De ella proviene directamente la figura del intermediario consagrada legalmente en el ordenamiento colombiano.

De ahí que una de las principales equivocaciones de la legislación colombiana esté en confundir la mediación con el mandato, pues la independencia frente a las partes que interactúan es uno de los aspectos cardinales de la mediación, y esta cuestión no es óbice para que en el desarrollo de las relaciones comerciales se puedan establecer contratos de mandato entre el intermediario y alguna de las partes aproximadas. Paralelamente, el legislador colombiano no se limitó a introducir el mandato en la intermediación por agencias y agentes, sino que en adición a él, decidió atribuirles la representación de las entidades aseguradoras bajo un esquema alejado de la realidad ya que esta clase de intermediarios no ejercen un mandato representativo como quiera que no celebran el contrato en nombre de otro, ni aceptan los riesgos en nombre de estos $\frac{10}{}$

Del mismo modo, el error legislativo que le atribuye facultades representativas a las agencias y los agentes exhibe sus falencias mediante las potestades mínimas contenidas en el artículo 42 del EOSF, considerando que con excepción del literal a) que les permite recaudar las primas, las prerrogativas allí enunciadas no requieren una representación efectiva y pueden ser ejecutadas en su calidad de aproximador o de promotor que incentiva la celebración de contratos de seguro. .11

\subsection{Las agencias asimiladas a corredores}

De un análisis superficial y simple, cuando se indaga por los tipos de intermediarios existentes en Colombia, se percibe con facilidad que una diferencia sustancial entre los corredores y las agencias radica en que los corredores están sometidos a la supervisión permanente. Una conclusión lógico-deductiva radicaría en asociar a los corredores como los intermediarios de mayor tamaño y mayor volumen de comisiones recibidas por negocios intermediados, lo cual puede ser una regla general, pero no necesariamente se cumple en todos los casos.

10 Ariza, R. (2008). Reflexiones sobre la naturaleza jurídica del intermediario de seguros en Colombia. 17(29).

11 Ordóñez, A. (2012). Estudios de Seguros. Bogotá: Universidad Externado de Colombia. 
En esa medida, sería un exabrupto desconocer que la dinámica misma del mercado le permite a cualquier intermediario aumentar su volumen de negocios; y por consiguiente, es inevitable cuestionar los límites divisorios para ser o no un intermediario vigilado.

Plenamente consciente de esta realidad social, el legislador buscó el mecanismo idóneo para asimilar a las agencias con mayor volumen de ingresos, que se reflejan en comisiones recibidas, con los corredores y su régimen de supervisión. Atendiendo a que en Colombia existen más de 10,000 agencias y agentes, solamente algunas de ellas podrían unirse a los corredores para entrar al espectro de supervisión. $\underline{\underline{12}}$

Tras esa lógica, asumiendo que los corredores de seguros efectivamente son los intermediarios de mayor envergadura, y los que necesariamente estarán sometidos a la vigilancia del supervisor, existen agencias que por la dinámica del mercado han logrado un crecimiento significativo hasta el punto de recibir por comisiones sumas superiores a las de un corredor, de suerte que pensando en ellas, el legislador incluyó en la normatividad la figura de agencias asimiladas a corredores.

Entonces, el Estatuto Orgánico del Sistema Financiero (EOSF) introdujo en el numeral 4 de su artículo 41 esta figura para establecer que respecto de las agencias con comisiones equivalentes o superiores a 800 salarios mínimos legales mensuales vigentes (SMLMV) en un ejercicio contable anual, el supervisor tendrá facultades de exigirles la reglamentación prevista para los corredores de seguros en el numeral 2 del artículo 40, en relación con el establecimiento de un capital mínimo y una organización técnica y contable. $\underline{13}$

En idéntico sentido pero de manera más específica, el Decreto 2605 del mismo año, 1993, señalaba el régimen aplicable a los intermediarios de seguros y reaseguros, fijando las condiciones para su supervisión. En este decreto se estableció un tope distinto y quedó consagrado que las agencias y agentes de seguros que causaran comisiones iguales o supe12 IMF . (2017). Country Report No. 13/50. En M. D. Galindo, N. Torres, \& L. y. Ruíz, Estudio de diagnóstico, Esquema de comercialización de seguros en Colombia. Bogotá: Publicaciones URF.

13 Superintendencia Bancaria de Colombia. (2004). Concepto 2003040628-3 (27 de febrero, 2004). Corredores de Seguros. Bogotá. 
riores a 1.600 SMLMV en un ejercicio contable anual, serían sujetos a la supervisión permanente de la Superintendencia Bancaria. Este decreto fue derogado y a la vez compilado en el Decreto 2555 de 2010, también conocido como el Decreto Único del Sector Financiero, que se encuentra vigente en la actualidad y la norma fue reproducida en su integridad en su artículo 2.30.1.2.1.

Esa fue la normatividad imperante en el ordenamiento colombiano hasta la entrada en vigencia de la Ley 510 de 1999, con la que se expidieron normas para el sector asegurador y las funciones de la Superintendencia Bancaria, cuyo artículo 101 estableció que la autorización de las agencias y los agentes para operar ya no se debía surtir ante la Superintendencia Bancaria, y en su lugar trasladó la responsabilidad a las entidades aseguradoras. Es decir, en concordancia con lo mencionado en líneas precedentes, con la proclamación del esquema de supervisión conocido como indirecto, aparentemente las agencias dejaron de ser competencia de la Superintendencia Bancaria, hoy Financiera, para serlo de las entidades aseguradoras a la luz de la representación que por expreso mandato legal profesan estos intermediarios sobre ellas.

Posteriormente, la Ley 964 de 2005 eliminó del artículo 325 del EOSF la expresión "agencias colocadoras de seguros", pues en este artículo disponía que le corresponde a la Superintendencia Financiera la vigilancia e inspección de las instituciones enunciadas en él. Esta norma terminó de consumar la tendencia legislativa planteada, en la que la verificación de los requisitos legales y la idoneidad de las agencias y agentes pasaron a ser definitivamente un asunto de competencia de las compañías aseguradoras.

A pesar del recuento normativo que se hace hasta este punto, el legislador nunca se pronunció respecto de la figura de las agencias asimiladas a corredores y se considera que esa nunca fue su intención, pues deseaba mantenerla incólume como institución.

Esta fue la posición de la doctora Rebeca Herrera Díaz, quien expuso que efectivamente el legislador jamás consideró derogar la figura de las agencias asimiladas, por lo que hoy en día la norma continúa en plena vigencia y en consecuencia, la Superintendencia Financiera conserva 
total facultad para ejercer su supervisión sobre las agencias inmersas en la causal descrita. $\stackrel{14}{ }$

Ahora bien, ha sido la misma Superintendencia Financiera la que se ha encargado de negar a sí misma la posibilidad de hacer uso de la facultad que el regulador le otorgó, y ello lo ha exteriorizado mediante sendos conceptos; inclusive con anterioridad a la expedición de la Ley 964 de 2005, toda vez que estimó que la aplicación de la figura de las agencias asimiladas era incompatible con el artículo 101 de la Ley 510 de 1999, que en opinión de este organismo, le sustrajo todas las facultades de supervisión sobre las agencias, y por ende, se configuró una derogatoria tácita del numeral 4 del artículo 41 del EOSF. $\underline{15}$

De igual manera, con posterioridad a la expedición de la Ley 964 de 2005, el supervisor argumentó que de acuerdo con el marco normativo vigente, la vigilancia de las entidades colocadoras de seguros "definitivamente" ya no era del resorte de ese organismo en virtud de la derogatoria proclamada por la Ley 964, que eliminó la expresión "agencias colocadoras de seguros" del artículo 325 del EOSF. Agregó que igualmente estas facultades se entendían derogadas tácitamente desde 1999, y que al margen de la incorporación del Decreto 2605 de 1993 en el 2555 de 2010, su aplicación también resulta incompatible con el marco normativo vigente. $\frac{16}{}$

Visto lo anterior, considera el autor del presente escrito que la SFC puede valerse en la actualidad del marco normativo expuesto para arrogarse las facultades de supervisión de las agencias y los agentes de seguros cuyos ingresos por comisiones igualen o superen los 1.600 SMLMV, pero no lo hace debido a una interpretación discutible del régimen aplicable. De hecho, el comportamiento del mercado demanda la supervisión de la Superfinanciera sobre actores muy importantes que continúan actuando con plena libertad bajo la modalidad de agencias. Tan es así que el proyecto de decreto que se materializó en la expedición del

$14 \quad$ Herrera, R. (2010). Intervención del Estado y regulación de las entidades aseguradoras en Colombia: ¿vamos en la dirección correcta? . 19(33).

15 Superintendencia Bancaria de Colombia. (2004). Concepto 2003040628-3 (27 de febrero, 2004). Corredores de Seguros. Bogotá.

16 Superintendencia Financiera de Colombia. (2013). Concepto 2012102090-002 (15, enero, 2013). Seguros, agencias colocadoras. Bogotá. 
Decreto 2123 de 2018, intentó derogar definitivamente la figura de las agencias asimiladas del Decreto 2555 pero fue suprimido del texto final.

\subsection{El esquema de supervisión indirecta sobre las agencias y agentes de seguros}

\subsubsection{Aspectos generales sobre la supervisión: bien} es sabido que las actividades aseguradora, bancaria y bursátil no constituyen la prestación de un servicio público en cabeza del Estado y/o particulares, sin embargo, tienen consigo un factor de riesgo connatural que hacen imperativa la necesidad de proteger el interés legítimo de la ciudadanía en ellas y por esto, son consideradas por expresa disposición constitucional como actividades de interés público. Por esta razón, el desarrollo y ejecución de las mencionadas actividades se podrá llevar a cabo únicamente con la previa autorización del Estado, quien intervendrá en la materia para garantizar su adecuado funcionamiento.

Asimismo, y en concordancia con lo anterior, el artículo 189 de la Carta Política le atribuye al Presidente de la República como Suprema Autoridad Administrativa, la prerrogativa de ejercer, de acuerdo con la ley, la inspección, la vigilancia y el control sobre las personas que realicen las actividades financiera, bursátil y aseguradora, de este modo:

El ejercicio de estas atribuciones, visto dentro del marco de la realización de los objetivos constitucionales que propenden por la satisfacción del interés general, constituye en realidad un modo de intervención estatal necesaria, al tiempo que se convierte en una herramienta operativa de la mayor utilidad para garantizar, en el escenario de las distintas actividades públicas, la observancia plena de las políticas que el Estado está llamado a implementar y ejecutar. $\cdot \underline{17}$

La misma Carta Magna en su artículo 150 expresa que serán funciones del Congreso de la República, en su calidad de legislador, dictar las normas generales señalando los objetivos y criterios a los cuales el

17 Corte Constitucional. (2001). Sentencia C-199 (21 de febrero, 2001). Control de constitucionalidad. Sala Plena. M.P.: Rodrigo Escobar Gil. Bogotá. 
gobierno debe sujetarse al regular las actividades financiera, bursátil y aseguradora, e igualmente, expedir las normas bajo las que el gobierno debe cumplir las funciones de inspección y vigilancia. El congreso está facultado entonces para modular la desconcentración de todas las funciones que por expreso mandato legal incumben al Presidente de la República, y en ese sentido, crear organismos especializados que bajo la dirección del gobierno, cumplan con las funciones de vigilancia. $\frac{18}{}$

Por consiguiente, en esta estructura del aparato administrativo, las superintendencias son organismos técnicos y especializados a los que se les atribuye esas funciones de inspección, vigilancia y control en la materia de su competencia, en la medida en que el Presidente se encuentra en imposibilidad física de llevarlas a cabo directamente.

En un principio, el Decreto 655 de 1925 en su artículo 8 distinguió a los agentes de los intermediarios al consagrar que las compañías, agentes o intermediarios que directa o indirectamente contribuyan a la celebración de cualquier contrato de seguros en Colombia, sin la respectiva autorización requerida, incurrirían en una multa impuesta por el Superintendente. Esta norma evidenció que todo tipo de intermediario, sin distinción alguna, se encontraba sometido al espectro de control de la Superintendencia.

1.6.2. La supervisión indirecta: Las directrices más recientes de la Asociación Internacional de Supervisores de Seguros (IAIS) (International Association of Insurance Supervisors por su sigla en inglés) apuntan a la optimización de los recursos de supervisión mediante la implementación de modelos equilibrados, considerando que se deriva de las políticas de regulación prudencial que buscan un equilibrio al otorgarle una mayor relevancia al comportamiento de los intermediarios frente a los consumidores. $\underline{\underline{19}}$

Desde la perspectiva de la supervisión, los aseguradores e intermediarios son dos partes independientes que requieren adecuarse a los reglamen$\underline{\text { tos y parámetros }}$ preestablecidos para cumplir con la protección del sistema 18 Ibídem

19 Asociación Internacional de Supervisores de Seguros. (2011). Principios básicos de seguros, estándares, guía y metodología de evaluación. Obtenido de IAIS: https://iaisweb.org/ file/34489/principos-basicos-de-seguros-estandares-guia-y-metodologia-de-evaluacion-assal 
financiero y sus usuarios. De ahí que resulta innegable que el consumidor financiero es un cliente para asegurador e intermediario, y por ello, el régimen de regulación que recae sobre ambos, así como la supervisión que se ejerza, debe ser coherente en aras de lograr la eficiencia pretendida.

Existen jurisdicciones a nivel mundial en las que la determinación de los requisitos legales que deben cumplir se toma a partir de la forma que el intermediario haya elegido para operar, es decir, ya sea en forma de corredor o de agente, y donde el volumen de sus operaciones es criterio relevante para el modelo regulatorio aplicable. También existen regulaciones en las que el único criterio empleado para definir la normatividad aplicable para un intermediario en particular, no es más que la distinción entre corredor y agente como forma que haya adoptado el intermediario para operar, y otras donde se analiza exclusivamente el volumen de las operaciones del intermediario.

En las legislaciones en las que existe la distinción entre agentes y corredores, comúnmente hay un consenso en que una de las grandes diferencias entre ambas figuras es que los aseguradores son responsables por la conducta de sus agentes, quienes actúan en su representación, mientras que los corredores suelen actuar en la defensa de los intereses de los asegurados, y en consecuencia, el asegurador no es responsable por las actuaciones de los corredores. Desde luego, lo anterior se trata de una concepción primaria que sirve como punto de partida, cuya rigidez se ve difuminada y adaptada para la realidad y las implicaciones prácticas del desempeño de los intermediarios en su correspondiente jurisdicción.

En este punto, es indispensable considerar que la supervisión permanente como monitoreo de la actividad de los intermediarios, puede adoptar varias formas dependiendo de diferentes factores tales como el número de intermediarios en el mercado, el volumen y la complejidad de sus actividades, además de los recursos con los que cuente el ente encargado de ejercer la supervisión para ello. Con todas estas limitantes, se hace necesario encontrar un balance en las actividades de supervisión, a través de las cuales la entidad responsable pueda tener el control de los asuntos bajo su competencia, seleccionando quiénes le deben reportar información directamente. $\underline{20}$

20 Ibídem 
Desde la perspectiva de la supervisión, los aseguradores e intermediarios son dos partes independientes que requieren adecuarse a los reglamentos y parámetros preestablecidos para cumplir con la protección del sistema financiero y sus usuarios. De ahí que resulta innegable que el consumidor financiero es un cliente para asegurador e intermediario, y por ello, el régimen de regulación que recae sobre ambos, así como la supervisión que se ejerza, debe ser coherente en aras de lograr la eficiencia pretendida.

Existen jurisdicciones a nivel mundial en las que la determinación de los requisitos legales que deben cumplir se toma a partir de la forma que el intermediario haya elegido para operar, es decir, ya sea en forma de corredor o de agente, y donde el volumen de sus operaciones es criterio relevante para el modelo regulatorio aplicable. También existen regulaciones en las que el único criterio empleado para definir la normatividad aplicable para un intermediario en particular, no es más que la distinción entre corredor y agente como forma que haya adoptado el intermediario para operar, y otras donde se analiza exclusivamente el volumen de las operaciones del intermediario.

En las legislaciones en las que existe la distinción entre agentes y corredores, comúnmente hay un consenso en que una de las grandes diferencias entre ambas figuras es que los aseguradores son responsables por la conducta de sus agentes, quienes actúan en su representación, mientras que los corredores suelen actuar en la defensa de los intereses de los asegurados, y en consecuencia, el asegurador no es responsable por las actuaciones de los corredores. Desde luego, lo anterior se trata de una concepción primaria que sirve como punto de partida, cuya rigidez se ve difuminada y adaptada para la realidad y las implicaciones prácticas del desempeño de los intermediarios en su correspondiente jurisdicción.

En este punto, es indispensable considerar que la supervisión permanente como monitoreo de la actividad de los intermediarios, puede adoptar varias formas dependiendo de diferentes factores tales como el número de intermediarios en el mercado, el volumen y la complejidad de sus actividades, además de los recursos con los que cuente el ente encargado de ejercer la supervisión para ello. Con todas estas limitantes, se hace necesario encontrar un balance en las actividades de supervisión, 
a través de las cuales la entidad responsable pueda tener el control de los asuntos bajo su competencia, seleccionando quiénes le deben reportar información directamente ${ }^{21}$

De estas necesidades surge el modelo conocido como supervisión indirecta adoptado en países como Colombia, Estados Unidos e India, cada uno con sus particularidades, pero partiendo de la premisa de que a cada asegurador le corresponde monitorear la conducta de los intermediarios y reportársela al supervisor. En el caso particular de Colombia, este modelo se adopta con relación a las agencias y los agentes, pues corresponde a los aseguradores verificar el cumplimiento de los requisitos legales, de idoneidad y de pertinencia de sus agentes, mientras que los corredores se encuentran en el espectro de vigilancia directa de la superintendencia.

\section{LAS SOCIEDADES CORREDORAS DE SEGUROS}

\subsection{Aspectos generales}

Al hablar del corredor es conveniente aseverar que existe una definición legal de esta figura contenida en el artículo 1340 del estatuto mercantil en el que se identifican los siguientes patrones característicos: i) su experticia o conocimiento en el área de su desempeño, dentro del cual a su vez se desarrolla ii) la labor de acercar a dos o más partes interesadas para la celebración de un negocio mercantil, iii) sin estar vinculado a ninguna de ellas, es decir, con independencia. Alineado con el Código de Comercio expedido en 1971, se expidió en marzo de 1972 el Decreto 361 por el cual se reglamentaron las normas en materia de corredores de seguros contenidas en el Código.

En lo concerniente a la remuneración que se deriva para aquella persona que ejecuta maniobras en pro del acercamiento de las partes, llamada corredor, se establece que esta, en primera medida se causa a partir del momento en que se celebre el negocio jurídico entre las partes que el intermediario puso en contacto con tal finalidad, y que esta será $21 \quad$ Ibídem 
asumida de manera conjunta y por partes iguales entre ellos. Esta disposición contenida en el artículo 1341 del Código de Comercio opera en forma supletiva, permitiendo a las partes involucradas estipular libremente la remuneración por intermediación. En ese sentido, en cuanto al corredor de seguros concretamente, la misma norma establece que su remuneración le corresponderá al asegurador. $\underline{22}$

Este contrato encuentra en el sector asegurador uno de los principales campos para su desarrollo específico; tomando como punto de partida el Código de Comercio, que consagra una especie de definición legal que para ser entendida integralmente debe ser interpretada de modo conjunto con la del corredor general contenida en el artículo 1340 mencionado anteriormente, toda vez que el artículo 1347 establece que los corredores de seguros son las empresas constituidas como sociedades comerciales con el objeto social exclusivo de "ofrecer seguros, promover su celebración y obtener su renovación a título de intermediarios entre el asegurado y asegurador".

En ese orden de ideas, el aspecto organizacional de los corredores de seguros como sociedades comerciales, además de excluir directamente la posibilidad de ostentar la calidad de corredor siendo persona natural, merece unas precisiones concretas ya que con la expedición del Código de Comercio en 1971 se consagró que estas sociedades debían ser colectivas o de responsabilidad limitada, sin embargo, la entrada en vigencia de la Ley 510 de 1999 les impuso la obligación de convertirse en sociedades anónimas.

Desde el punto de vista legal, los corredores son los intermediarios de seguros que están más ampliamente regulados por la normatividad en general, teniendo en cuenta la existencia de preceptos normativos que rigen su actividad en el Código de Comercio, en la Ley 65 del 66, de la que varias disposiciones en la materia hicieron tránsito al acápite correspondiente al Estatuto Orgánico del Sistema Financiero; la Ley 510 de 1999, a través de la cual se introdujo la obligación de modificar el tipo societario a las sociedades anónimas y el Decreto 2555 de 2010.

22 Corte Suprema de Justicia. (2011). Sentencia Ref. Expediente. 11001-3103-013-200100900-01. Sala de Casación Civil.M.P.: Edgardo Villamil Portilla. Bogotá. 


\subsection{Objeto social ¿exclusivo?}

En el derecho societario la actividad de las sociedades mercantiles se encuentra supeditada a lo previsto en su objeto social, y en esa medida, es este un requisito esencial de toda sociedad que además, debe especificar de manera clara la totalidad de sus actividades principales.

Por supuesto, con la enunciación de las actividades principales se entienden incluidas todas las directamente relacionadas con ellas y las necesarias para el ejercicio de los derechos, por un lado, y el cumplimiento de las obligaciones, por otro, lo que en otras palabras significa que "existe un objeto principal conformado por las actividades económicas indicadas como marco general trazado por voluntad de los contratantes; y un objeto secundario, que está compuesto por la serie de actos que la compañía puede realizar en desarrollo de aquellas" $\underline{\underline{23}}$

Las normas del objeto social que, en teoría, son aplicables a los corredores de seguros como sociedades anónimas, se complementan con normatividad propia de su actividad de la que surgen particularidades sobre el objeto social de esta clase de intermediarios.

Sin duda alguna, la primera singularidad proviene de la definición legal que el Código de Comercio contempla para el corredor de seguros, debido a que en ella se circunscribe el objeto social de ellos a efectuar exclusivamente las actividades mencionadas en él, a saber, el ofrecimiento de los seguros; promover la celebración de estos contratos y buscar la renovación de los mismos. El asunto anterior, contrastado con el funcionamiento de los intermediarios del mercado asegurador, dista bastante de la realidad genuina de la ejecución de actividades de corretaje en dicho sector. Esa exclusividad del objeto social como tal, desde la entrada en vigencia del Código de Comercio hasta el día de hoy, ha venido perdiendo legitimidad, no solo por causa de una realidad que se le escapa por completo, sino porque el mismo legislador mediante la consagración de normas posteriores, se ha encargado de atribuirles nuevas funciones que son diferentes a las contempladas en la norma inicial.

23 Superintendencia de Sociedades. (1997). Resolución 360-1498 (31 de julio, 1997). Bogotá; Reyes, F. (2011). Derecho Societario. Tomo I, 2a edición. Bogotá: Editorial Temis. 


\subsubsection{Apertura del mercado para la adquisición de se- guros por parte de las entidades del sector público: con la} promulgación de la Ley 45 del 90 que expidió directrices generales para la actividad aseguradora, se expandió significativamente el campo de acción de los intermediarios de seguros, toda vez que se modificaron las disposiciones del Decreto Ley 222 de 1983 que establecía que todos los seguros, cuyo objeto consistiera en proteger el patrimonio o bienes de las entidades públicas, debían contratarse "forzosamente" con una compañía de seguros estatal, siempre y cuando el valor asegurado o el interés asegurable no superase el valor de $\$ 120.000 .000$. Adicionalmente, en caso de superar la cuantía establecida para la contratación forzosa, la selección de la compañía aseguradora debía hacerse mediante licitación pública, con la particularidad de que si la compañía estatal participaba de la misma en igualdad de condiciones con los particulares, debía adjudicársele el contrato y en aquellos casos en los que se seleccionaba una entidad aseguradora diferente, la entidad elegida debía ofrecerle en coaseguro a la aseguradora pública al menos el 30\% del riesgo.

No obstante lo anterior, las entidades estatales en búsqueda de cobertura de seguros, estaban legitimadas para eludir el proceso licitatorio si decidía contratar directamente con la entidad aseguradora con capital del Estado. ${ }^{4}$

En ese sentido, la consecuencia lógica de lo anterior es la colocación de pólizas cuyos tomadores, asegurados o beneficiarios fueran entidades públicas en cabeza de La Previsora S.A. compañía de seguros, dado que fue la única compañía estatal existente durante la vigencia de la mencionada norma. De ahí que la Ley 45 del 90 fue una gran ventaja en materia comercial para las entidades aseguradoras e intermediarios de seguros porque se les permitía a las primeras, competir en igualdad de condiciones con la aseguradora del Estado, y para las segundas, se abría una brecha en búsqueda de mejores condiciones de asegurabilidad en el mercado.

Por esta causa se amplió el espectro para las labores de intermediación tanto de los corredores, y en definitiva, la organización de licitaciones en igualdad de condiciones, generó una oportunidad muy propicia para los corredores de seguros de prestar sus servicios de asesoría a las entidades públicas.

24 Penagos, A. (2005). El seguro de cumplimiento en la contratación administrativa. Bogotá: Trabajo de grado (presentado para optar el título de abogado) Pontificia Universidad Javeriana, Facultad de Ciencias Jurídicas. p. 21. 


\subsubsection{Reforma estructural del Sistema de Seguridad}

Social: en 1993 se hizo un gran avance en cuanto a crear un sistema integral de seguridad social en Colombia; con la sanción de la Ley 100 se buscaba garantizar las prestaciones económicas y asistenciales en materia de salud, pensiones y riesgos laborales.

Con lo anterior, algunas de las premisas del marco normativo recién consagrado para el sistema de seguridad social, el artículo 287 de la misma Ley le permitió a las entidades encargadas de la prestación de estos servicios realizar actividades de promoción, ventas, la administración de la relación con sus afiliados, el recaudo, pago y transferencia de los recursos a través de intermediarios de seguros. En la actualidad los sistemas de salud, pensiones, y principalmente de riesgos laborales, con sus particularidades emplean a los corredores de seguros.

\subsubsection{Efectos de las regulaciones complementarias:} consecuentemente, deviene elocuente la manera en que legislativamente, con posterioridad a la expedición del Código de Comercio en el que se consagró el objeto social exclusivo de los corredores de seguros, el desarrollo normativo y la práctica misma los han llevado a prestar más servicios de los que contempló la norma inicialmente.

Indirectamente, la misma Superintendencia Financiera por medio de pronunciamientos ha reconocido esta realidad en los siguientes términos:

No es jurídicamente viable la constitución de una corredora de seguros bajo un tipo societario distinto a sociedad anónima, teniendo en cuenta que además, su objeto social debe recaer, de manera exclusiva, en la promoción y el ofrecimiento de contratos de seguro y demás actividades legalmente autorizadas, dentro de las cuales se encuentran la de promoción y participación de los intermediarios de seguros en cada uno de los regímenes de los sistemas generales que integran el Sistema de Seguridad Social Integral regulado por Ley 100 y sus normas reglamentarias. .25

Esta particularidad sobresaliente del objeto social de los corredores es destacada por el docente, José Orlando Montealegre Escobar, quien opta 25 Superintendencia Financiera de Colombia. (2015). Concepto 2015033118-002 (25 de mayo, 2015). Corredores de seguros, constitución, tipo societario. Bogotá. 
por llamarlo "objeto social regulado" en razón a que dicho objeto de las sociedades corredoras no se encuentra circunscrito exclusivamente a las actividades enunciadas inicialmente en el Código de Comercio, sino que con la expedición de normas posteriores, el legislador le ha conferido nuevas facultades para el desarrollo de su actividad comercial. $\underline{26}$

Ahora bien, existe la posición jurídico-doctrinaria que asegura que al margen del caso particular de los corredores de seguros, todas las entidades vigiladas por la Superintendencia Bancaria, hoy Superintendencia Financiera, podrán tener dentro de su objeto social únicamente las actividades que les sean autorizadas legalmente; lo anterior marca una diferencia radical entre los corredores y demás intermediarios, pues por causa de esto, ellos no podrán ejecutar simultáneamente los quehaceres inherentes al corretaje de seguros y actividades sin relación de conexidad con aquellos. ${ }^{27}$ Lo anterior concuerda con el artículo 2034 del Código de Comercio que impone a cargo de la SFC la obligación de hacer cumplir a sus vigiladas las normas societarias cuando no pugnan con las normas imperativas de carácter especial que recaen sobre ellas.2.2.2.1. La protección a través de la información

\subsection{La constitución de sociedades corredoras de seguros como entidad vigilada por la superintendencia financiera de Colombia}

El EOSF y el artículo 1351 del Código de Comercio disponen que solo podrán ser corredores de seguros, las sociedades que se encuentren debidamente inscritas ante la Superintendencia Financiera, que mantengan vigente el certificado expedido por ese organismo para tal efecto, lo que implica la obtención de una licencia.

El funcionamiento de una persona jurídica a título de corredor de seguros indefectiblemente se encuentra sometido a la autorización previa del supervisor, por ello, está precedida de un complejo proceso de constitución de la entidad que se debe surtir ante dicha dependencia, presentada

\footnotetext{
26 Montealegre, J. O. (2016). Cátedra sobre intermediarios de seguros en la especialización en Derecho de Seguros. Bogotá: Pontificia Universidad Javeriana.

27 Superintendencia Financiera de Colombia. (2010). Concepto 2010012904-002 (29 de marzo, 2010). Objeto social bancos, servicios de asistencia. Bogotá.
} 
toda la documentación que para el efecto dispone la Superintendencia, en la lista de chequeo M-LC-AUT-001 disponible para consulta en su página web.

El proceso de constitución de una entidad vigilada es bastante engorroso y le exige a los futuros accionas revelar su información financiera y personal por completo, de manera que si con el mismo capital, se puede elegir entre ser entidad vigilada o no serlo, entre surtir un proceso de constitución o no hacerlo, entre tener un objeto social regulado o no tenerlo, teniendo bajo ambas figuras la posibilidad de ser intermediario, ¿por qué un inversionista preferiría ser corredor sobre agencia?

\subsection{El carácter independiente de los corredores}

Conviene reiterar que una de las características que el Código de Comercio le atribuyó a la actividad de corretaje en general, es poner en contacto a las partes interesadas en la celebración de un negocio comercial, sin para eso estar vinculado con ninguna de ellas por relaciones de colaboración, dependencia, mandato o representación. Ese categórico rasgo impuesto legalmente en Colombia, presenta una serie de amplias dificultades y falencias a la hora de explicar, desde la perspectiva de la teoría general del negocio jurídico, la actividad de los corredores, y su particular importancia dentro del mercado asegurador nacional, considerando que en adición a procurar la celebración del contrato y sus posteriores renovaciones, su conocimiento especializado los ha llevado a brindar constantes asesorías, principalmente a los asegurados.

Esto significa que las funciones atribuidas por el legislador a los corredores de seguros indicarían que sus labores cesan en el momento en que se logra el perfeccionamiento del contrato de seguro entre las partes contactadas por intermedio de ellos, y se reanudarían al final de cada vigencia en aras de gestionar una renovación o prórroga del negocio. No obstante, la práctica exhibe diariamente que sus funciones no cesan con el perfeccionamiento del contrato, sino que una vez celebrado el mismo, inician unas labores de acompañamiento paralelas frente a la ejecución de un contrato. 
Ante la problemática planteada, el doctor Andrés Eloy Ordóñez Ordóñez atribuyó el anterior fracaso legislativo para regular desde una perspectiva jurídica la actividad de los corredores de seguros, a la intención de los redactores del Código de Comercio colombiano de adoptar una óptica legislativa de origen italiano, en la cual se concibió al corredor como un ente ajeno a los vínculos contractuales con alguna de las partes del negocio, en el que sirvió exclusivamente como aproximador entre ellas. $\frac{28}{}$ El Código de Comercio Terrestre que rigió hasta la entrada en vigencia del Código de Comercio actual, proclamaba en su artículo 331 al corretaje como una de las modalidades del mandato a través de la cual una persona le encargaba a otra, mediante una remuneración o en forma gratuita, la ejecución de uno o más de sus negocios lícitos.

De esta manera, el propósito del legislador consistió en desprender la figura del corretaje en todas sus expresiones frente al contrato del mandato, semejante a la legislación italiana, de modo tal que eventualmente, si de las relaciones que mantiene el corredor con cualquiera de las partes que pretende aproximar surge algún tipo de mandato, este será meramente accidental y completamente ajeno a las actividades naturales del mismo.

En ese sentido, continúa el doctor Ordóñez exponiendo las inconsistencias fehacientes que supuso la emancipación legislativa de los contratos de corretaje y mandato, cuyas repercusiones son palpables cuando se trata de seguros, teniendo en cuenta que en primer lugar, como se señaló anteriormente, la función del corredor de seguros se circunscribe a la celebración de "actos de comercio" y no a actos jurídicos como lo contempla la legislación de origen, y segundo, que se les atribuye la función de hacer ofrecimientos de seguros, toda vez que de aceptarse esta tesis, los corredores están efectuando un acto que no es de su competencia porque las mismas solo pueden provenir de quien esté en condiciones de prestar el servicio, y por este motivo, la legislación de forma implícita, los está poniendo dentro del escenario de un contrato de mandato. $\frac{29}{}$

Asimismo, refiriéndose a un estudio realizado sobre este punto por el doctor Hernando Tapias Rocha, manifestó que se trató de una mala 
reproducción de una normatividad extranjera que omitió incluir el artículo 1761 del código italiano, mediante el que se permite al mediador o intermediario obtener la representación de alguna de las partes del contrato perfeccionado con su intervención, para actos relacionados con la ejecución del mismo.

Dicho esto, no cabe duda de que las falencias en las definiciones legales consagradas en un sistema normativo tienen como consecuencia casi lógica la multiplicidad de interpretaciones de las mismas, cuando la realidad de una actividad concreta no puede ser explicada a partir de las normas preexistentes. En el tema de marras, la figura del mediador traída de la doctrina italiana se confunde con el mandato entre las partes, dado que al mediador no se le desconoce que con posterioridad a la celebración del negocio jurídico mediado, en su calidad de intermediario pueda realizar actividades conexas o adicionales que jurídicamente constituyen un claro mandato. $\frac{30}{}$ Española indica que este es un "mandatario que como comerciante acreditado, actúa por cuenta de uno o varios. .11

En últimas, es indispensable aceptar que el corredor desde el inicio mismo no actúa por iniciativa propia procurando la celebración del contrato porque la esencia misma del corretaje siempre actúa en desarrollo de un encargo que el interesado real le confiere, sin que esto implique actuar en representación. ${ }^{32}$ Salvo facultad expresa por una de las partes del contrato, este no se celebra en nombre o representación de una de ellas, aunque, y si así llegara a suceder, el escenario varía de manera considerable porque ya no se está actuando a título de intermediario sino que estas actuaciones inequívocas los convierten en auténticos mandatarios ${ }^{33}$.

En el escenario ideal de una ejecución tal como lo concibe la norma, y como se desprende esencialmente de la figura de la mediación propugnada por la doctrina legal italiana, su actividad genera contratos principales y autónomos de mediación con cada uno de los extremos. ${ }^{34}$ 30 Ariza, R. A. (2008). Reflexiones sobre la naturaleza jurídica del intermediario de seguros en Colombia. 17(29, 95-126.).

31 Real Academia Española. (s.f.). “Corredor, ra” $\{$ En Línea $\}$. Obtenido de http://dle.rae. es/?id=AxUOPpI

32 Sánchez, F. (1986). Instituciones de Derecho Mercantil, 12a Edición. Madrid: Editoriales de Derecho Reunidas.

33 Ariza, 2008, op. cit.

34 Ibídem

Rev.Ibero-Latinoam.Seguros, Bogotá (Colombia), vol. 28 (50): 83-118, enero-junio de 2019 
Resulta apenas natural y lógico que las personas después de conocer la gestión del mediador y percibir en forma directa su conocimiento en un área específica, prefieran valerse de este mismo por ser experto y garantizar una adecuada representación de sus intereses en la celebración de un negocio especializado. $\underline{35}$

En conclusión, en coherencia con la opinión del doctor Ordóñez, se ha de pensar que el esquema legal colombiano de absoluta independencia, espontaneidad e iniciativa propia del corredor para el desarrollo de sus actividades inherentes, no se acomoda a la realidad, y resulta cuando menos contradictorio, considerando que entre los corredores e interesados en la celebración del negocio se generan relaciones contractuales distintas a la mediación propiamente dicha.

Se trata entonces de una normatividad ambigua que obliga a realizar esfuerzos interpretativos para entender que más que una manifestación del contrato típico de prestación de servicios, se trata del contrato de corretaje en lo que estrictamente le permite la ley; ello le genera al corredor obligaciones de medios frente a las partes que intervienen en el negocio, mientras que adicionalmente, las circunstancias pueden llevar a concretar situaciones en las que el intermediario obre como un auténtico mandatario representando a una de las partes. $\frac{36}{} \mathrm{El}$ tema no ha sido ajeno a la jurisprudencia de la Corte Suprema de Justicia, de la cual emana el fragmento que se cita a continuación:

En este orden de ideas, la Corte considera que solo en la medida en que se verificara una actividad dirigida a ofrecer seguros, promover su celebración y obtener su renovación, que es la actividad intermediadora que establece el art. 1347 del C. de Comercio, se estaría en presencia de un contrato de corretaje. Otras funciones, entre ellas la asesoría para la elaboración del pliego de licitación, pueden adicionar o complementar la actividad del corredor, pero per se y aisladamente consideradas, no pueden estructurar el contrato de corretaje. De modo que la asesoría así prestada, como fue la que la parte demandante desarrolló frente a la demandada, tomadora de los seguros con ocasión del llamado público

35 Betancourt, M. (1996). Derecho privado: categorías básica. Bogotá: Universidad Nacional de Colombia.

36 Ordóñez, A. (2012), op.cit. 
de la licitación, correspondería con independencia de su eficacia a un contrato de prestación de servicios o a otro de naturaleza similar, pero no a uno de corretaje. $\frac{37}{}$

Como se observa, la Corte no desconoce que tanto en la etapa precontractual, como en la ejecución del contrato mediado, se pueden dar actividades conexas o complementarias al objeto social exclusivo de los corredores, que no contrarían en forma alguna la esencia de la actividad descrita, siempre y cuando, no sean ajenas a la actividad consagrada en sus estatutos como principal y fundamental, por ejemplo, la asistencia en caso de siniestro, la asesoría pertinente para actualizaciones o modificaciones del contrato.

En adición a la inconsistencia normativa, visto desde una perspectiva práctica, la labor de los corredores en una gran parte se resume en orientar a los asegurados en temas de tarifas, amparos y selección de un asegurador, es decir, gestionan por cuenta de los intereses de uno de los futuros contratantes y no se limitan a aproximar las partes, recibiendo legitimación expresa por parte de los asegurados para administrar su perfil de riesgos asegurables y mantenerse constantemente en la búsqueda de mejores condiciones. Paralelamente, la actividad de los corredores, aunque mayormente se encuentra orientada a prestar servicios a los tomadores y/o asegurados, puede ser facultada por las entidades aseguradoras para recibir primas o dineros relacionados con la ejecución del contrato, además de expedir pólizas. (en forma de notas de cobertura) ${ }^{38}$

En este contexto, parece evidente que la definición legal de corredor de seguros en la normatividad colombiana resulte a todas luces insuficiente y contradictoria en la medida en que está lejos de contemplar todas las actividades que llevan a cabo estos intermediarios, además de atribuirle un objeto social exclusivo circunscribiéndolo a unas actividades concretas, y emancipándolo de la figura del mandato cuando, por ejemplo, en la función de ofrecer seguros en sí misma concurren ambas figuras. Está visto también que su gestión no se encuentra supeditada a las actividades consagradas en la ley; es por ello que todo el estado del

37 Corte Suprema de Justicia. (2000). Sentencia (8 de agosto, 2000). Ref. Expediente 5383. Sala de Casación Civil. M.P.: José Fernando Ramírez Gómez. Bogotá.

38 López, H. (2014). Comentarios al contrato de seguro. Bogotá: Dupré Editores Ltda. 
arte de la discusión plasmada en este escrito deviene de una falencia legislativa propia del ordenamiento nacional.

A manera de ejemplo y de conclusión, resulta conciso mencionar que la Unión Europea, definió la mediación de seguros como toda actividad de trabajo en la etapa precontractual a la celebración de un contrato de seguro, su celebración, o la asistencia en la gestión y ejecución del contrato, sobre todo en caso de siniestro. $\frac{39}{}$

\section{CONCLUSIONES}

- La agencia de seguros constituye un contrato distinto a la agencia del Código de Comercio y tampoco se trata de una subespecie de esta que funcione en el mercado asegurador.

- Por otra parte, la representación que sobre las entidades aseguradoras ejercen los agentes y agencias debe ser entendida, salvo expresa disposición en contrario, únicamente respecto de las facultades mínimas conferidas en el artículo 42 del EOSF, de manera que no toda actuación de estos intermediarios obliga a los aseguradores representados.

- La representación que opera por expresa disposición normativa no ilustra la cercanía del intermediario con los extremos de la relación negocial, considerando que en ocasiones la agencia/agente vela por los intereses del asegurado, y esto a su vez puede suscitar conflictos de interés.

- Actualmente se exige a las agencias de seguros constituirse como sociedades de responsabilidad limitada, colectivas o en comandita simple, fundándose en una errónea interpretación normativa.

- En la legislación italiana, de donde proviene la figura de la intermediación consagrada en Colombia, aquella no está revestida de prerrogativas propias del mandato, ni representación. Es decir que la representación

39 Parlamento Europeo y Consejo de la Unión Europea. (2002). Directiva 2002/92/CE (9 de diciembre, 2002). Sobre la mediación en los seguros. 8 p. Art. 2, numeral 3. Bruselas. 
que le fue atribuida a agencias y agentes fue creación del legislador nacional, desnaturalizando la figura del intermediario.

- La figura de las agencias asimiladas a corredores no fue derogada tácitamente por la normatividad que excluye a las agencias y agentes del espectro de vigilancia de la Superfinanciera, sin embargo, el supervisor lo ha dado por sentado tras adoptar el esquema de supervisión indirecta.

- Se requiere que la Superfinanciera haga uso de la figura de las agencias asimiladas a corredores debido a que hay agencias que por el volumen de negocios intermediados anualmente, merecen ser vigiladas.

Otro de los efectos adversos que se pueden derivar de la inaplicación o derogatoria tácita de las agencias asimiladas a corredores es desincentivar la correcta inversión de los recursos destinados a la intermediación de seguros.

- Si bien el estatuto mercantil consagra que el objeto social de los corredores se limita exclusivamente al ofrecimiento y la promoción para el perfeccionamiento de contratos de seguro, el legislador les amplió el espectro para participar en el sistema de seguridad social y asesorar a entidades en la contratación de sus seguros. Por ello es correcto hablar de objeto social regulado y no de objeto social exclusivo.

- El carácter independiente que el estatuto mercantil le atribuye a los corredores, indicando que no podrán tener relación de dependencia, o representación con ninguna de las partes, desconoce que entre los corredores y las partes aproximadas, con posterioridad al perfeccionamiento del negocio celebrado, pueden darse relaciones de las características descritas.

\section{REFERENCIAS}

Ariza, R. (2008). Reflexiones sobre la naturaleza jurídica del intermediario de seguros en Colombia. 17(29). 
Ariza, R. A. (2008). Reflexiones sobre la naturaleza jurídica del intermediario de seguros en Colombia. 17(29, 95-126.).

Asamblea Constituyente. (1991). Constitución Poítica de Colombia. Bogotá: LEGIS.

Asociación Internacional de Supervisores de Seguros. (2011). Principios básicos de seguros, estándares, guía y metodología de evaluación. Obtenido de IAIS: https://iaisweb.org/file/34489/principos-basicos-de-seguros-estandares-guia-y-metodologia-de-evaluacion-assal

Betancourt, M. (1996). Derecho privado: categorías básica. Bogotá: Universidad Nacional de Colombia.

Congreso de la República. (1996). Ley 65. Por la cual se reglamenta la profesión de Agente Colocador de Seguros. Diario Oficial 32087. Art. 12. Bogotá.

Congreso de la República. (2005). Ley 964 . Diario Oficial No. 45.963 de 08 de julio de 2005. Bogotá.

Corte Constitucional. (2001). Sentencia C-199 (21 de febrero, 2001). Control de constitucionalidad. Sala Plena. M.P.: Rodrigo Escobar Gil. Bogotá.

Corte Constitucional. (2009). Sentencia C-354 . Sala Plena. M.P.: Gabriel Eduardo Mendoza Martelo. Bogotá.

Corte Suprema de Justicia. (2000). Sentencia (8 de agosto, 2000). Ref. Expediente 5383. Sala de Casación Civil. M.P.: José Fernando Ramírez Gómez. Bogotá.

Corte Suprema de Justicia. (2001). Expediente 5817. Octubre 22/01. Sala de Casación Civil. MP Jorge Antonio Castillo Rúgeles. Bogotá, Colombia.

Corte Suprema de Justicia. (2011). Sentencia Ref. Expediente. 110013103-013-2001-00900-01. Sala de Casación Civil.M.P.: Edgardo Villamil Portilla. Bogotá. 
Herrera, R. (2010). Intervención del Estado y regulación de las entidades aseguradoras en Colombia: ¿vamos en la dirección correcta? . 19(33).

IMF . (2017). Country Report No. 13/50. En M. D. Galindo, N. Torres, \& L. y. Ruíz, Estudio de diagnóstico, Esquema de comercialización de seguros en Colombia. Bogotá: Publicaciones URF.

López, H. (2014). Comentarios al contrato de seguro. Bogotá: Dupré Editores Ltda.

Ministerio de Hacienda y Crédito Público. (2010). . Decreto 2281 (25 de junio, 2010). Por el cual se reglamenta la Defensoría del Consumidor Financiero. . Diario Oficial. 47.751 del 2010. Bogotá.

Montealegre, J. O. (2016). Cátedra sobre intermediarios de seguros en la especialización en Derecho de Seguros. Bogotá: Pontificia Universidad Javeriana.

Ordóñez, A. (2012). Estudios de Seguros. Bogotá: Universidad Externado de Colombia.

Parlamento Europeo y Consejo de la Unión Europea. (2002). Directiva 2002/92/CE (9 de diciembre, 2002). Sobre la mediación en los seguros. 8 p. Art. 2, numeral 3. Bruselas.

Penagos, A. (2005). El seguro de cumplimiento en la contratación administrativa. Bogotá: Trabajo de grado (presentado para optar el título de abogado) Pontificia Universidad Javeriana, Facultad de Ciencias Jurídicas. p. 21.

Presidencia de la República. (1971). Código de Comercio . Decreto 410. Diario Oficial No. 33.339 del 16 de junio de 1971. Bogotá, Colombia.

Presidencia de la República. (1983). Decreto Ley 222 . Diario Oficial N. 36189. 9, Bogotá.

Presidencia de la República. (1993). Decreto 2605 . Diario Oficial N. 41151. 23. Bogotá. 
Presidencia de la República. (1993). Decreto 663[Estatuto Orgánico Del Sistema Financiero]. Diario Oficial No. 40.820, del 5 de abril de 1993. Bogotá.

Presidencia de la República. (1999). Ley 510 . Diario Oficial 43654, 4 de Agosto de 1999. Bogotá.

Presidencia de la República. (2010). Decreto 2555 (15 de julio, 2010). Por el cual se recogen y reexpiden las normas en materia del sector financiero, asegurador y del mercado de valores y se dictan otras disposiciones. . Diario Oficial No. 47.771 de 15 de julio de 2010. Bogotá.

Presidencia de la República. (2018). Decreto 2123 . Diario Oficial de Colombia, 15 de Noviembre de 2018. Bogotá.

Real Academia Española. (s.f.). “Corredor, ra” \{En Línea $\}$. Obtenido de http://dle.rae.es/?id=AxUOPpI

Reyes, F. (2011). Derecho Societario. Tomo I, 2a edición. Bogotá: Editorial Temis.

Sánchez, F. (1986). Instituciones de Derecho Mercantil, 12a Edición. Madrid: Editoriales de Derecho Reunidas. .

Superintendencia Bancaria de Colombia. (2004). Concepto 2003040628-3 (27 de febrero, 2004). Corredores de Seguros. Bogotá.

Superintendencia de Sociedades. (1997). Resolución 360-1498 (31 de julio, 1997). Bogotá.

Superintendencia Financiera de Colombia. (1996). Concepto 96023487-3 (23 de agosto, 1996). Concepto. Diferencias. Derechos del agente. Delegación de la profesionalidad. Bogotá.

Superintendencia Financiera De Colombia. (2004). Concepto 20040190021 (20 de mayo, 2004). Estatutos excepcionales; personas autorizadas para desarrollar la actividad. Bogotá. 
Superintendencia Financiera de Colombia. (2007). Concepto $2006065802-$ 004 . ara proveer la eficiencia y seguridad de la actividad de colocación de seguros, con la responsabilidad que entraña la oferta y promoción de los contratos de seguros... Bogotá.

Superintendencia Financiera de Colombia. (2010). Concepto 2010012904002 (29 de marzo, 2010). Objeto social bancos, servicios de asistencia. Bogotá.

Superintendencia Financiera de Colombia. (2013). Concepto 2012102090002 (15, enero, 2013). Seguros, agencias colocadoras. Bogotá.

Superintendencia Financiera de Colombia. (2015). Circular Externa 50 . Ref.: Instrucciones sobre los requisitos de idoneidad para la intermediación de seguros, el deber de información frente a los consumidores de seguros y el Sistema Unificado de Consulta de Intermediarios de Seguros. Bogotá.

Superintendencia Financiera de Colombia. (2015). Concepto 2015033118002 (25 de mayo, 2015). Corredores de seguros, constitución, tipo societario. Bogotá. 